\title{
Successful Treatment of Biliary Atresia in Very Small Infants through Living Related Liver Transplantation
}

\author{
Chunbao Guo Mingman Zhang \\ Department of Hepatobiliary Surgery, Children's Hospital, Chongqing Medical \\ University, Chongqing, P.R. China
}

\section{Key Words}

Liver transplantation · Living donor · Infant · Biliary atresia

\begin{abstract}
Improving outcomes in very small children is a major goal of pediatric liver transplantation. This report describes our experience of living related liver transplantation in an infant weighing $3.98 \mathrm{~kg}$. The recipient, a 80-day-old male infant with congenital biliary atresia, was treated with living donor liver transplantation and then followed up for 6 months. The left lateral segment (segment II, III) with reduced size from the donor, his 26-year-old mother, was used as the graft. The graft weighed $200 \mathrm{~g}$. The graft weight to recipient body weight ratio was $5.025 \%$. The donor regained her liver function within 3 days and was discharged on day 8 . The patient showed good results. Liver function returned to normal 9 days after the operation with bilirubin level almost decreased to normal. Cyclosporin, mycophenolate mofetil and prednisone were used for postoperative immunosuppression. No bleeding, thrombosis, infection or bile leakage occurred. The patient had slight fever because of a little collection in the abdomen and recovered after paracentesis and drainage. He was discharged on day 16 . The donor and recipient are in satisfactory condition at present. Improvement of technique in hepatic surgery, microsurgical technique in vascular surgery and postoperative intensive care are the keys to ensure the success of the procedure.
\end{abstract}

\section{Introduction}

Biliary atresia is the most common cause of chronic cholestasis in infants and children. The incidence of biliary atresia in infants is estimated at 3.7:10,000 and Kasai hepatoportoenterostomy helps these pediatric patients survive beyond infancy. Liver transplantation is indicated when the Kasai procedure fails to work or when patients 
develop progressive deterioration of liver function [1]. In 1967, Starzl performed the first liver transplantation in a pediatric patient [2]. However, liver transplantation in young infants under the age of 1 year and children with a body weight below $13 \mathrm{~kg}$ had a high risk of morbidity and mortality and so were initially contraindicated. Additionally, because of the small size of the patients, grafts were difficult to obtain. Living donor liver transplantation was developed to alleviate organ shortage from deceased donors [3]. With advances in surgical technique, liver reduction, reduced-size liver transplantation extended liver transplantation to small infants. Now liver transplantation is accepted as an established treatment for children with acute and chronic liver failure, especially for biliary atresia. In many series, the risk of postoperative complications and rates of retransplantation are higher in children less than 1 year old [4]. Goss et al. [5] demonstrated that before 1993 one-year survival in patients under 1 year old was 64\%, while one-year survival increased to $84 \%$ after 1994. Little data exist exclusively on very young or very small infants (less than 3 months old or $<5 \mathrm{~kg}$ ) who have undergone liver transplantation [3]. This report describes our experience with fully performing a living related liver transplantation technically more difficult for a 3-month-old infant weighing $3.98 \mathrm{~kg}$ with genital biliary atresia.

\section{Methods}

\section{The Recipent}

An 80-day-old male child born of a nonconsanguineous marriage presented with abdominal distension since 1 month of age. Jaundice, highly colored urine and clay-colored stools were noticed since birth. There was no family history of a similar disorder. When admitted to our hospital, he was jaundiced with marked splenomegaly. At the time of referral, the child was $51 \mathrm{~cm}$ in height, weighed $3.98 \mathrm{~kg}$ and had a temperature of $37.5^{\circ} \mathrm{C}$, jaundice, abdominal distension and moderate

hepatosplenomegaly. Laboratory examination revealed the following data: hemoglobin $10.5 \mathrm{~g} / \mathrm{dl}$; white blood cells $6,500 / \mathrm{mm}^{3}$; alkaline phosphatase $224 \mathrm{U}$; serum glutamic oxaloacetic transaminase 1,230 U; serum glutamic pyruvic transaminase $70 \mathrm{U}$; total bilirubin $215.3 \mu \mathrm{mol} / \mathrm{l}$; direct bilirubin $169.4 \mu \mathrm{mol} / \mathrm{l}$; total protein $56.6 \mathrm{~g} / \mathrm{l}$; albumin $26.2 \mathrm{~g} / \mathrm{l}$; prothrombin time $28.9 \mathrm{~s}$. Ultrasonography of the abdomen showed coarse liver echotexture with an intrahepatic multicystic mass predominantly involving the left lobe of the liver and extending up to the porta hepatis. These channels were partly extrahepatic. The gallbladder, common bile duct and portal vein could not be identified separately. Splenomegaly, ascites and minimal right-sided pleural effusion were also noted on ultrasonography. Computed tomographic scan of the abdomen revealed moderately dilated central intrahepatic biliary radicals in the left Iobe. These radicals showed continuity with the extrahepatic cystic spaces. The common bile duct was not identifiable separately from these radicals. The kidneys were normal. A magnetic resonance cholangiopancreatography was performed which showed multiple intrahepatic and extrahepatic cysts without visualization of the common bile duct. Some of the biliary radicals noted at the periphery of the liver did not communicate with the dilated cystic lesion at the porta hepatis and produced distortion of the liver anatomy. This was interpreted as an manifestation of cystic change in a patient with biliary atresia. A color Doppler study of the heart rules out congenital cyanotic heart disease. Contrastenhanced echocardiography (using agitated saline injected in a peripheral vein) showed the appearance of contrast bubbles on the right side of the heart followed by the left side with a delay of 3 cardiac cycles, suggesting the presence of pulmonary arteriovenous fistulae. Liver biopsy and further surgical procedure were not possible because of refusal by the parents and due to poor prognosis. The child was treated using diuretics and multivitamins as recommended for a case of cholestasis.

\section{The Donor}

The living donor was his mother, a 26-year-old woman with blood group A, ABO identical to the patient. There was no biochemical or serologic evidence of liver disease for the donor. The hematologic, biochemical and urological analyses and the scintigraphic, radiologic and tomographic evaluations of the donor showed no abnormality. Accurate knowledge of the patient's anatomy is essential to plan 
subsequent steps for surgical anastomosis. Computed tomography with volumetric measurement was performed to assess the volume of the left lateral lobe in order to determine the graft to be harvested (fig. 1). Angiographic evaluation showed that the donor had little blood vessel variations. The left hepatic artery was derived from the right anterior hepatic artery, which was nearly inside the liver

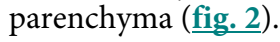

\section{Donor Surgery}

An abdominal approach by bilateral subcostal incision was used with an upward midline extension to the xiphoid process. The falciform and left triangular ligaments, part accida and condensa of the gastrohepatic omentum were sectioned to mobilize the left liver. After dissecting the portal vascular pedicle and the left hepatic vein, intraoperative ultrasound was used to determine the configuration of the left hepatic vein, the junction of the middle hepatic vein with the left hepatic vein, and to mark on the liver surface the position of the middle hepatic vein, which would be the liver transection plane. The transection line was determined by the optimal graft volume and the anatomy of its drainage veins and marked with electrocautery on the liver surface. All of the right and left hepatic venous branches were traced to the periphery in the medial segment to confirm the distribution of these structures in the left lateral segment. Hilar dissection was performed to free the left hepatic artery and portal vein. The portal pedicle was identified with ultrasound guidance within the left lateral segment. Cholecystectomy was performed and the cystic duct was cannulated for cholangiography using undiluted radiographic contrast in order to delineate the ductal anatomy. The cholangiography showed that it had similar variation to the portal vein (fig. 3 ). Once the liver was mobilized, the left hepatic vein, left hepatic artery and left portal vein were isolated and the left hepatic duct was divided, the parenchyma was sectioned. With the use of the dissection and ligation technique, the left lateral lobe was detached well to the right of the attachment of the falciform ligament from the main part by intraoperative ultrasonography with an ultrasonic dissector, leaving the left portal vein, left hepatic artery and left hepatic vein intact. The dissection of the left hepatic artery was partly inside the liver parenchyma and the left duct was divided close to the cut surface of the liver, with an intact Glissonian sheath when the liver transection was finished. The left hepatic duct was divided near the confluence of the bile ducts. The left lateral bisegmental graft, consisting of the left lateral segment (LLS, segments II, III), was further reduced according to previous reports $[6,7]$. The isolated graft was perfused in situ with the left portal vein clamped and cannulated by a catheter connected with cold lactated Ringer's solution followed by a cold University of Wisconsin solution when the left hepatic vein was opened. The computed tomographic scan volume of the lateral segment was $297.198 \mathrm{~cm}^{3}$. The weight of the implanted lateral segment was $200 \mathrm{~g}$, measured by fluid displacement.

\section{Recipient Surgery}

Hepatectomy was performed in a separate operating room. The abdomen was entered through a bilateral subcostal incision with midline extension. Hilar dissection was performed to isolate and divide branches of the hepatic artery and portal vein. It was laborious as a result of inflammation and fibrosis around the hepatoduodenal ligament. Some technical difficulties were encountered, including dissection of the portal vein and separation of the bile duct. After dissection and ligation of the hepatic arteries, the portal vein and bile duct were clamped en masse. Just before the recipient hepatectomy, the donor graft was removed and the portal vein and hepatic artery perfused with cold University of Wisconsin solution. The left suprahepatic vein was implanted in a new ostium on the anterolateral surface of the vena cava using the ostium of the right suprahepatic vein as one of the sides of this triangular orifice with a 4-0 continuous prolene suture. The ostium of the donor suprahepatic vein was sectioned as close to the hepatic parenchyma as possible to avoid outfow problems. The openings in the middle and left suprahepatic veins were closed. Portal reconstruction was performed by end-to-end anastomosis to the truncated bifurcation of the recipient portal vein with a 6-0 prolene suture. Once completed, the hepatic artery was reconstructed to the recipient hepatic artery using microvascular techniques with the aid of microscopy (original magnification $\times 310$ ) using a $7-0$ prolene suture. A short interposition vein graft from the donor liver was inserted. The great saphenous vein was harvested from the donor for a length of $5 \mathrm{~cm}$ in a standard fashion noting the direction of flow, which can prove life-saving under these circumstances. The graft was then revascularized, and hemostasis was performed. The total ischemic time was $3 \mathrm{~h} 20 \mathrm{~min}$. The transplanted liver started to function after completion of portal vein anastomosis followed by hepatic artery reconstruction. Intraoperative color flow Doppler ultrasound was performed to demonstrate vascular flow patterns, pulsatility and velocities after vessel reconstruction, before and after abdominal closure for early detection of possible vascular complications. The falciform ligament was reconstructed in left-side grafts. Extreme care to prevent air 
and particulate embolism in the cava was done by flushing the graft with lactated Ringer's solution before completion of hepatic vein and portal anastomoses. Biliary reconstruction was performed with interrupted polypropylene 7-0 sutures with extramucosal knots. The left hepatic duct was anastomosed end-to-side to the Roux-en-Y loop of jejunum with an internal stent after the hepatic artery anastomosis. After securing hemostasis, both the donor and the recipient abdomens were closed by placing a closed suction drain in the retroperitoneal space for each patient. The donor received $3 \mathrm{U}$ blood, and the recipient received $6 \mathrm{U}$ during the procedure. Table 1 summarizes recipient and donor parameters.

\section{Immunosuppression and Follow-Up}

Postoperative immunosuppression consisted of azathioprine ( $2 \mathrm{mg} / \mathrm{kg} /$ day i.v.), prednisolone $(2.5 \mathrm{mg} / \mathrm{kg} /$ day i.v. $)$ and cyclosporine. Cyclosporine is administered orally one day after transplantation at a dose of $3 \mathrm{mg} / \mathrm{kg} /$ day divided into two doses, except for cases with hepatic encephalopathy and severe infection. The target posttransplantation whole blood trough concentration of cyclosporine was 250-350 ng/ml during the first 3 months and around 150-250 ng/ml thereafter. Steroids were started on graft reperfusion at a dose of $10 \mathrm{mg} / \mathrm{kg}$ and then gradually reduced from $1 \mathrm{mg} / \mathrm{kg} /$ day to $0.3 \mathrm{mg} / \mathrm{kg} /$ day over the first month. The child began to recover after surgery. The postoperative day was uneventful. There was no steroid-resistant rejection or chronic rejection. Similarly, there were no obvious postoperative complications. Persistent arterial hypertension requiring medication was not seen in this recipient. Liver function improved persistently (table 2). There were no significant differences in the preoperative and 6-month postoperative levels of cholesterol, triglyceride, uric acid, and fasting blood glucose. Height and weight greatly improved after operation. The postoperative course of the donor was uneventful. A slight elevation of bilirubin (total $4.3 \mathrm{mg}$; direct $2.3 \mathrm{mg}$ ) occurred during the first $48 \mathrm{~h}$, but returned to normal within a couple of days, and she was ready to be discharged on the seventh postoperative day. Three months after surgery, she began to work as laboriously as before the operation and is still doing well.

\section{Discussion}

Biliary atresia continues to be the most frequent indication in children or infants for liver transplantation. Liver transplantation in infants represents a major medical and technical challenge, particularly in babies weighing $<5 \mathrm{~kg}[1,8]$. Before 1990 , the absence of appropriate full-sized grafts and the technical difficulties encountered in learning to reduce larger livers led to poor outcomes in infants less than 1 year of age. Small recipients less than 1 year of age or weighing $<5 \mathrm{~kg}$ are typically prone to complications with a one-year survival of $64 \%$, compared with $75 \%$ of older pediatric recipients $[9,10]$. This is consistent with the results from our institution, which demonstrate a $20 \%$ graft survival and $25 \%$ patient survival in transplants done prior to 2008 in infants $<5 \mathrm{~kg}$. Retransplantation was common, predominately for vascular complications with portal vein thrombosis and primary nonfunction occurring more frequently in the younger age groups, which frequently led to loss of graft and death of the patient; the mortality rate was approximately $50 \%$. Liver transplantation was not considered by some groups in infants weighing $<3 \mathrm{~kg}$ [11]. The explanation for this was mainly anatomical. For example, the calibre discrepancy of the graft and recipient hepatic artery understandably leads to a higher incidence of vascular complications [12]. Mazzaferro et al. [13] suggested that arteries $<3 \mathrm{~mm}$ are at an increased risk of thrombosis, in a $2 \mathrm{~mm}$ or less vessel for the left lateral segment graft. Even the use of a microscope would not ameliorate the increased risk of thrombosis in this situation, but recipient age is not a factor in hepatic artery thrombosis. With the development of reduction hepatectomy, but also with advances in medical and nursing expertise, weight alone $(<7 \mathrm{~kg})$ should not be considered a contraindication for liver transplantation [9]. Liver transplantation in infants weighing $<7 \mathrm{~kg}$ is technically demanding but feasible and can still be performed with good outcome [14]. Some groups have reported their experience with liver transplantation in infants 
during the first 3 months of life, with a mean weight at the time of transplantation of $3.4 \pm$ $1 \mathrm{~kg}$ [15]. Our patient was weighing $<5 \mathrm{~kg}$ at the time of transplantation and had not previously undergone hepatic portoenterostomy (Kasai procedure).

The size of the donor is an important consideration, since in a small child it is important to avoid a large-for-size graft, which is associated with complications. A graft-to-recipient weight ratio of more than $5 \%$ constitutes a large-for-size graft [16]. This may cause a reduced vascular inflow, which may be further compounded by compression of the graft and vessels by a tight abdominal closure. Surgical techniques must be adapted for adequate graft preparation, vascular reconstruction and abdominal closure [16-19]. The Kyoto group reported monosegmental graft transplantation. This group has recently published their experience in vascular reconstruction in infants weighing $<6 \mathrm{~kg}$, reporting a low incidence of hepatic outflow complications (1.5\%) and a portal vein and hepatic artery complication rate of 14 and $7.7 \%$, respectively [20]. In our patient, the mean weight ratio between donor and recipient was 5.025. It is important to avoid compression of the graft or right lung, and temporary abdominal closure (using a silastic patch if necessary) is advisable in cases where there is any degree of tightness. Tailoring graft size to the size of the recipient is paramount in pediatric liver transplantation. The reduced left lateral segment technique used in this procedure is a safe and useful alternative to monosegmental liver transplantation. This technique has been developed to provide a transplanted liver graft of sufficient parenchymal mass, whilst limiting the potentially serious problems of a large-for-size graft in a small recipient, i.e. insufficient blood flow to the revascularized liver and too tight an abdominal closure, which may cause graft compression, or the need for prosthetic abdominal wall closure. We have found that the technique is safe and does not compromize the vascular supply and drainage of the liver graft [6]. We have not experienced problems with delayed closure and have not seen an increase in wound infection in these patients for using a reduced left lateral segment liver graft, in common with other authors [6-8]. This patient, when staying in the pediatric intensive care unit after liver transplantation, was also intraabdominal pressuremonitored by direct and indirect methods, especially if mechanically ventilated.

As published in other studies, infectious complications average around $65 \%$ of patients and result in mortality in $>50 \%$ of patients $[21,22]$. In common with our previous data, infection was a major problem in $10(62 \%)$ of our previous patients [22]. Sepsis was the most frequent infection, affecting 5 (31\%) of the infants but causing no deaths. Cytomegalovirus and Adenovirus have been implicated as the leading viral cause of morbidity and mortality in children [23]. This patient had a prolonged and complicated hospital course with Cytomegalovirus positivity, but was treated successfully with cidofovir and discharged home. Standard treatment with minimization of immunosuppression, ganciclovir or acyclovir, and intravenous immunoglobulin has not demonstrated consistent success.

With the increasing availability of living donors, many centers have now published their experience with improved techniques for liver grafts from living donors also showing good results [24-26]. Liver transplantation for infants weighing $<5 \mathrm{~kg}$ can be technically challenging but can have equivalent graft and patient survival when compared to larger children requiring liver transplantation. The significant improvement of survival for liver transplantation with infants weighing $<5 \mathrm{~kg}$ through surgical technique improvement was similar to that of infants $>5 \mathrm{~kg}$. The infant described here is recognized as the youngest liver transplantation recipient in China. Infants should not be denied liver transplantation based on weight alone. 


\section{Acknowledgement}

The authors wish to express their gratitude to all of the transplant coordinators, nursing staff, and administrative personnel, without whom this work would not have been possible, in particular Lin Mo, Zhimei Ren, Yuan Shi, Lin Bo, Yingliang Li, Qilin Li, Yi Tang and Qiao Wang. They would also like to thank their previous and current transplant fellows for their diligent and tireless work: Lvnan Yan, Conglun Pu, Yingcun Li, Quan Kang, Xianqing Jin, Yuhua Deng, Xiaoke Dai, Qiang Xiong, Kai Chen and Xiaomei Zhu. The research was supported in part by the Key Project of the Chongqing Natural Science Foundation (CSTC, 2008BA0021).

Table 1. Summary of recipient and donor operative variables

$\begin{array}{ll}\text { Total operative time, min } & 552 \\ \text { Cold ischemia, min } & 60 \\ \text { Warm ischemia, min } & 32 \\ \text { Blood type combinations (D-R) } & \text { A-A } \\ \text { Graft weight, g } & 200 \\ \text { Graft/recipient ratio, \% } & 5.025 \\ \text { Venous graft (length), cm } & 4 \\ \text { Blood loss, ml } & 260 \\ \text { Packed red cell transfusion, ml } & 100\end{array}$

Table 2. Preoperative and postoperative summary of liver function in the recipient

\begin{tabular}{llll}
\hline & $\begin{array}{l}15 \text { days after } \\
\text { transplantation }\end{array}$ & $\begin{array}{l}5 \text { days after } \\
\text { transplantation }\end{array}$ & $\begin{array}{l}\text { On } \\
\text { admission }\end{array}$ \\
\hline Total bilirubin $(2.0-20), \mu \mathrm{mol} / \mathrm{l}$ & 17.2 & 56.6 & 215.3 \\
Direct bilirubin $(0-4), \mu \mathrm{mol} / \mathrm{l}$ & 6.9 & 36.5 & 169.4 \\
Alkaline phosphatase $(0-20), \mathrm{U} / \mathrm{l}$ & 74 & 94 & 224 \\
Gamma glutamyl transferase $(0-50), \mathrm{U} / \mathrm{l}$ & 85 & 79 & 162 \\
Albumin (33-52), g/l & 32.9 & 28.9 & 26.2 \\
Prothrombin time $(9-16), \mathrm{s}$ & 14 & 17 & 28.9 \\
APTT (28-39), s & 36 & 46 & 66 \\
\hline
\end{tabular}




\begin{tabular}{r|l|l|l} 
Case Reports in & $\begin{array}{l}\text { Case Rep Gastroenterol 2010;4:158-167 } \\
\text { D01: 10.1159/000314195 }\end{array}$ & Published online: May 12, 2010 & $\begin{array}{l}\odot \text { 2010 S. Karger AG, Basel } \\
\text { ISSN 1662-0631 } \\
\text { www.karger.com/crg }\end{array}$ \\
\hline
\end{tabular}

Fig. 1. The liver parenchyma was excised well to the right of the attachment of the falciform ligament.

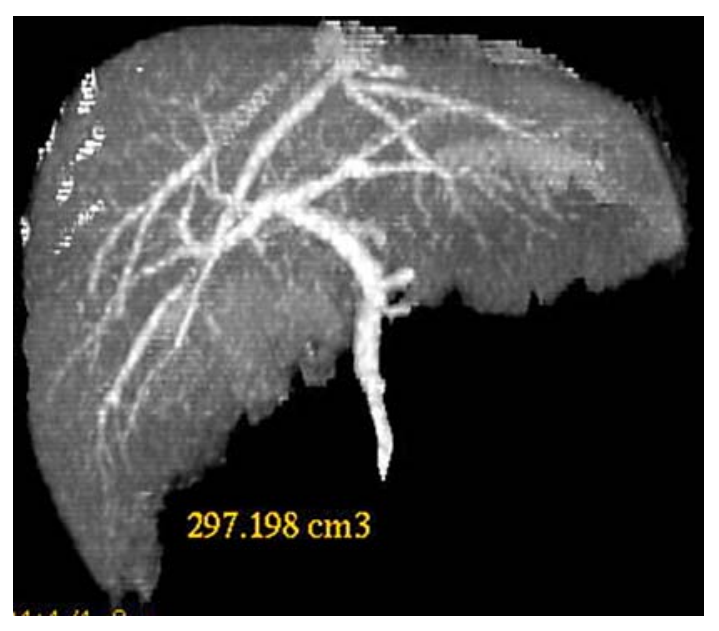

Fig. 2. Donor hepatic angiogram showing normal arterial structure.

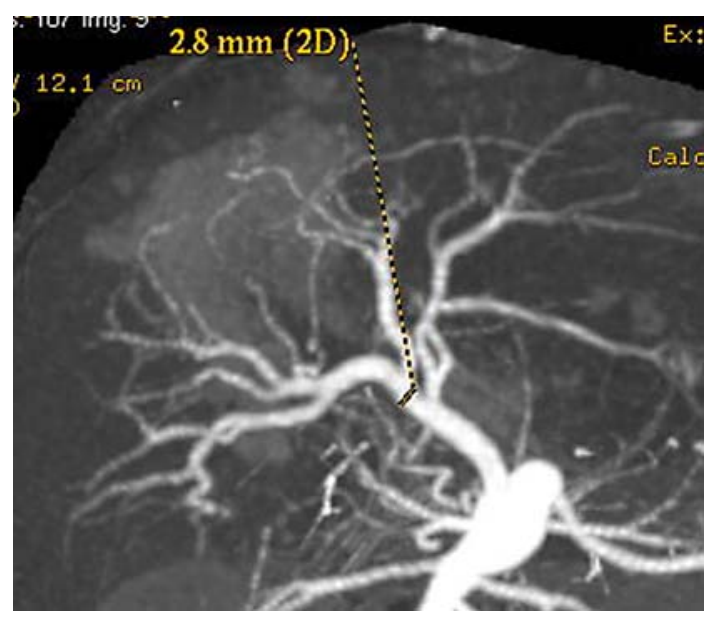


Fig. 3. Cholangiography of the donor. Two branches of right bile duct (anterior and posterior right bile ducts) of the mother.

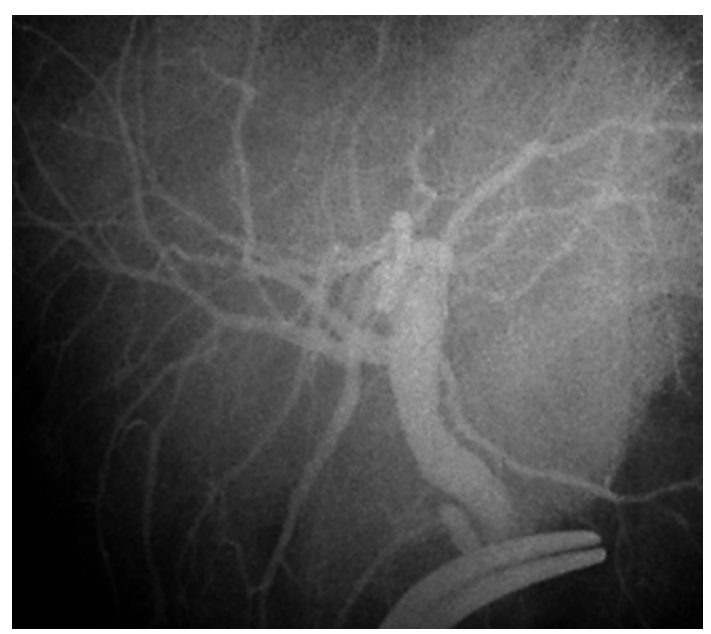




\section{References}

1 Wang SH, Chen CL, Concejero A, et al: Living donor liver transplantation for biliary atresia. Chang Gung Med J 2007;30:103-108.

2 Starzl TE, Koep LJ, Schröter GP, et al: Liver replacement for pediatric patients. Pediatrics 1979;63:825-829.

3 Tiao GM, Alonso M, Bezerra J, et al: Liver transplantation in children younger than 1 year - the Cincinnati experience. J Pediatr Surg 2005;40:268-273.

4 Mekeel KL, Langham MR Jr, Gonzalez-Peralta RP, et al: Liver transplantation in very small infants. Pediatr Transplant 2007;11:66-72.

5 Gross JA, Shackleton CR, Maggard M, Swenson K, Seu P, McDiarmid SV, Busuttil RW: Liver transplantation for fulminant hepatic failure in the pediatric patient. Arch Surg 1998;133:839-846.

6 Attia MS, Stringer MD, McClean P, et al: The reduced left lateral segment in pediatric liver transplantation: an alternative to the monosegment graft. Pediatr Transplant 2008;12:696-700.

7 Kasahara M, Fukuda A, Yokoyama S, et al: Living donor liver transplantation with hyperreduced left lateral segments. J Pediatr Surg 2008;43:1575-1578.

8 Noujaim HM, Mayer DA, Buckles JA, et al: Techniques for and outcome of liver transplantation in neonates and infants weighing up to 5 kilograms. J Pediatr Surg 2002;37:159-164.

9 Haberal M, Karakayali H, Arslan G, et al: Liver transplantation in children weighing less than $10 \mathrm{~kg}$. Transplant Proc 2006;38:3585-3587.

10 López-Santamaria M, de Vicente E, Gámez M, et al: Pediatric living donor liver transplantation. Transplant Proc 2003;35:1808-1809.

11 Durand P, Debray D, Mandel R, et al: Acute liver failure in infancy: a 14-year experience of a pediatric liver transplantation center. J Pediatr 2001;139:871-876.

12 Kasahara M, Kaihara S, Oike F, et al: Living-donor liver transplantation with monosegments. Transplantation 2003;76:694-696.

13 Mazzaferro V, Esquivel CO, Makowka L, Belle S, Kahn D, Koneru B, Scantlebury VP, Stieber AC, Todo S, Tzakis AG, et al: Hepatic artery thrombosis after pediatric liver transplantation - a medical or surgical event? Transplantation 1989;47:971-977.

14 Iglesias J, López JA, Ortega J, et al: Liver transplantation in infants weighing under 7 kilograms: management and outcome of PICU. Pediatr Transplant 2004;8:228-232.

15 Ogawa K, Kasahara M, Sakamoto S, et al: Living donor liver transplantation with reduced monosegments for neonates and small infants. Transplantation 2007;83:1337-1340.

16 Kiuchi T, Kasahara M, Uryuhara K, et al: Impact of graft size mismatching on graft prognosis in liver transplantation from living donors. Transplantation 1999;67:321-327.

17 Meyburg J, Hoerster F, Weitz J, et al: Use of the middle colic vein for liver cell transplantation in infants and small children. Transplant Proc 2008;40:936-937.

18 Haberal M, Sevmis S, Karakayali H, et al: A novel technique for hepatic arterial reconstruction in living-donor liver transplant. Exp Clin Transplant 2007;5:585589.

19 Jiang XZ, Yan LN, Li B, et al: Arterial complications after living-related liver transplantation: single-center experience from West China. Transplant Proc 2008; $40: 1525-1528$.

20 Shirouzu Y, Kasahara M, Morioka D, et al: Vascular reconstruction and complications in living donor liver transplantation in infants weighing less than 6 kilograms: the Kyoto experience. Liver Transpl 2006;12:1224-1232.

21 Jain A, Mazariegos G, Kashyap R, et al: Pediatric liver transplantation in 808 consecutive children: 20-years experience from a single center. Transplant Proc 2002;34:1955-1957.

22 Zhang M, Guo C, Yan L, et al: Successful treatment of Epstein-Barr virusassociated haemophagocytic syndrome arising after living donor liver transplantation. Hepatol Res 2009;39:421-426. 
23 Carter BA, Karpen SJ, Quiros-Tejeira RE, et al: Intravenous cidofovir therapy for disseminated adenovirus in a pediatric liver transplant recipient. Transplantation 2002;74:1050-1052.

24 Enne M, Pacheco-Moreira L, Balbi E, et al: Liver transplantation with monosegments. Technical aspects and outcome: a meta-analysis. Liver Transpl 2005;11:564-569.

25 Ogawa K, Kasahara M, Sakamoto S, et al: Living donor liver transplantation with reduced monosegments for neonates and small infants. Transplantation 2007;83:1337-1340.

26 Haberal M, Sevmis S, Karakayali H, et al: Outcome of pediatric liver transplant in grafts with multiple arteries. Pediatr Transplant 2008;12:407-411. 